https://doi.org/10.48009/1_iis_2009_77-86

\title{
COMPARING THE EFFECTIVENESS OF PUBLIC VS. PRIVATE BLOGGING IN A MANAGEMENT INFORMATION SYSTEMS STRATEGY COURSE
}

\author{
Malu Roldan, San Jose State University, roldan_m@cob.sjsu.edu \\ Ashraf Shirani, San Jose State University, shirani_a@ cob.sjsu.edu
}

\begin{abstract}
This paper reports on a study of the use of blogs to support a Management Information Systems Strategy class requiring higher level thinking skills. Comparison of the use of private vs. public blogs showed that public sites were more effective in providing students with the skills to assess the potential of emerging technologies and to integrate blogs into their daily activites.
\end{abstract}

Keywords: Web 2.0, Blogs, MIS Strategy, Information Systems education, Capstone Course

\section{INTRODUCTION}

An ongoing challenge for educators is identifying ways of motivating current generations of students found in our classrooms. The disconnect among generations of professors and generations of students has brought on differing expectations about learning and classroom dynamics. Nowhere is this disconnect most obvious as in the application of technologies. Current generations of students - generally identified as millennials - have grown up with easily available information technologies and connectivity. They are the "technology natives" while their professors have become the "digital immigrants" who are struggling to learn, let alone apply new technologies in the classroom [15].

This disconnect is especially challenging in classes where higher-order thinking skills are necessary, such as that required in capstone courses. When students are expected to recall, apply, and integrate knowledge gained from earlier courses into novel situations, the difficulty and uncertainty of the task tends to overwhelm both learners and teachers alike.

One way of addressing these challenges is to create learning spaces that integrate technologies most familiar to students. The hope is that these technologies will attract and motivate students to put more effort into their studies and, consequently, learn more of the material and be able to apply the knowledge in situations requiring higher-order thinking skills.
This paper reports on a study of the application of Web 2.0 technologies in a capstone MIS strategy class. Web 2.0 is the second-generation conceptualization of the Internet as a platform supporting applications built to harness collective intelligence [14]. It has spawned a range of social media sites facilitating the growth of digital communities and user-generated content. For this study, the focus is on blogs and how they might be used to give students practice with higher-order thinking skills. The assumption was that the use of a technology that is highly familiar and attractive to students would enable them to learn and apply more of the higher order thinking skills required in the capstone strategy class.

Blogs started out as publicly accessible, online personal journals but have evolved into widely read, harbingers of the most current information (often scooping mainstream media) - albeit at varying levels of credibility. Blogs are responsible for the emergence of alternative sources of information, particularly with the appearance of blog rating services - e.g. technorati - that track the socially determined value of various blogs, for example, based on the number of sites that link to a given blog post. Lately, traditional information organizations and well-established authors have co-opted the technology for their own musings and other material.

This study compares two ways of implementing blogging technologies to support course activities: First, a public platform that had students publish their blogs directly on a public site where they were accessible globally; and second a private platform where students had the chance to refine their posts before providing their permission to make them available to the general public. Differences in student learning outcomes show that the public blogs led to better learning of course skills than the private blogs.

\section{Millenials, Web 2.0, and Higher Order Thinking Skills}

Howe and Strauss [7] coined the term millennials to refer to the generation of students born from 1982 to the early 2000s. Millennials make up the baby 
boomlet resulting from baby boomers' late entry into parenthood. Distinguishing traits of this generation are that they are deemed special by previous generations, are sheltered, confident, team-oriented, achieving, pressured to excel, and conventional [7, page 45]. The first generation of millennials entered college in the beginning of the $21^{\text {st }}$ century. The learning style of this generation has been characterized as leaning towards "teamwork, experiential activities, structure, and the use of technology" [13, page 38].

Millennials (also known as Gen Y) view technology as an integral part of the environment. Born after the introduction of the personal computer, many of this generation were using computers before even starting grade school [9]. Eighty six percent of students acquired their first computer before starting college, and eighty eight percent of them access the Internet at least once a day [4]. Not surprisingly, this generation has fueled the rapid growth of Web 2.0 [8]. Merging their collaborative nature with their facility with technology, millennials make up over half of the visitors to facebook, the social networking site most popular among college age users $[8,12]$

Since about 2004, graduating seniors in our capstone courses have been members of the millennial generation. Capstone courses are especially challenging for both faculty and students because they require students to apply higher-order thinking skills in a learning environment that is more ambiguous than most of their earlier courses. While these courses require all the types of thinking in Bloom's taxonomy, the focus is on the three associated with the highest cognitive complexity: analysis, synthesis, and evaluation [2]. Furthermore, the information search, analysis, and composition requirements in a capstone course are associated with high uncertainty and stress [10]. Being close to the final course in a student's undergraduate career, the capstone-course learning environment tends towards less structure. Gone are the weekly drills and stepby-step instructions of earlier courses. To prepare students for applying their skills in a real-world environment, it is important to include a measure of the ambiguity of the real world in these courses.

Blogs have the potential to engage students in the difficult task of applying higher order thinking skills to create knowledge. Their Web 2.0 pedigree places the task within the realm of millennials' culture and preferences. At the same time, blogs can serve the same purpose as the daily journal that writers keep, both to document their experiences and reflect on them. Kulthau [10, page 141] recommends journaling as a way to "promote private reflection that can help users to make connections in and inferences about the information they have encountered and to see gaps that need further investigation." As such, blogs provide students with an informal forum for constructing meaning from the material they have gathered for their capstone papers. These serve as short, early drafts of portions of their final papers that not only help them organize their findings and reflections but also point to gaps in the information they have so far collected.

Two blog structures that are especially helpful for the information seeking and construction process are traditional blogs and social bookmarking sites. Traditional blogs (e.g. blogger.com) can be used as the place where students reflect on material they have read and start to synthesize this learning in preparation for writing their term papers. Social bookmarking sites (e.g. del.icio.us) enable students to build an online, categorized listing of materials they have identified to match a specific topic. In effect, students are building an annotated bibliography that allows them to associate searchable tags and a short note to a given resource. Students can also search through the social bookmarking site to identify sources that other users have identified for a given topic.

For the reasons stated in the previous paragraphs, there is much that recommends blogging technologies as teaching tools. Already, many learning management systems (e.g. Moodle, Desire2Learn) and other learning and collaboration platforms (e.g. tikiwiki, the google suite, sharepoint) offer blogging modules. Because these technologies are so new, we know very little about their effectiveness and about the best way in which they might be integrated into the classroom. This paper presents an early study to understand the implementation decisions to consider when integrating blogs into our classroom activities.

In particular, we will focus on the impact of private vs. public blogging platforms on a student's confidence in his/her ability to apply higher order thinking skills. In a private posting platform, students post blogs initially into a private online platform that is accessible only to the professor. The student decides when the blog will become accessible to the public over the world wide web. This situation can be achieved using an application such as tikiwiki managed by the professor or computing staff. In a public posting situation, each student's blog is accessible to the general public upon posting. This latter situation can be provided using a range of free 
hosted blogging services such as google's blogger.com.

The blogging platform parameter can impact learning in two contrasting ways. First, private posting supports a formative learning process to occur in a private setting. A student can post a blog into a private web space where a professor can give the student feedback for improving the blog in private. Access to the blog can be changed to public when appropriate. In contrast, all edits in a public blogging platform are visible to the general public as soon as they are posted. Second, public posting ups the ante for students composing their blogs. The added pressure of having a publicly visible blog may either encourage better first versions than those produced in a private setting, or the added pressure may just overwhelm students and result in poor performance. Millennials may react to this pressure in surprising ways. Judging from the tone and content of pages found in myspace and facebook. millennials have a penchant for performance and self-promotion. A public blog may be one that is more motivating because it feeds into this desire to perform. Some theorists will say that millennials are using Web 2.0 as a sort of experimentation platform. These platforms provide them with a setting for expressing and trying out different personas as they try to figure out their own unique identities [6]. Hence, it is possible that students have very little embarrassment attached with posting drafts and publicly edited material onto their blogs.

To shed some light on these various possibilities, the next section will discuss the research design and methodology we used to determine whether type of blogging platform has a significant effect on students' confidence with their higher order thinking skills. We then use the latter two sections to discuss our findings and conclusions.

\section{RESEARCH METHODOLOGY}

Our study centered on the following research question: What is the best way to implement blogging technologies to facilitate students' development of higher order thinking skills? We assumed that the formative feedback afforded by the private Web 2.0 platform provides a more effective learning experience for students to practice the application of higher order thinking skills. Formative feedback from instructors is a common teaching method for teaching students difficult learning tasks. Furthermore, students in the first semester of this class requested the private blogging platform as a way of improving the class. On the assumption that students, being technology natives, are quite knowledgeable about how they would best learn on a Web 2.0 platform, we tested the following hypotheses:

H1. Students using private blogs are more likely to have stronger confidence in their ability to apply higher order thinking skills than students using public blogs.

H2. Students using private blogs are more likely to have stronger confidence in their ability to apply emerging Web 2.0 technologies than students using public blogs.

To test the hypotheses, this study compares two groups of students taking a capstone MIS Strategy class using a field experiment design. The same instructor taught the class in two separate semesters - Fall 2007 and Spring 2008 - in a large metropolitan university in the Western United States. Both classes had the same learning goals, design, and requirements. Both classes incorporated blogs to provide students with an engaging platform for the knowledge seeking and construction activities - e.g. summary and integration of readings -- they undertook to develop their final term papers. Teams of four students worked on the final term paper: a vision for how an emerging technology could transform and industry and a company within that industry. Team members split up the research and writing required for the paper, and project management responsibilities. Blogs were written independently by each student in the class to help in the analysis and knowledge construction efforts to cover his/her topic assignment.

Students' confidence in higher order thinking skills was measured using a self-report survey based on Compeau and Higgins [3]. We adapted the authors' strength scales to focus on self-efficacy with use of blogging technology and with higher order thinking skills as implemented in course activities. Selfefficacy is a concept from social psychology developed by Bandura [1] that measures a person's (e.g. student) confidence that he/she can perform the behaviors necessary to achieve desired outcomes (e.g. assess the potential of an emerging technology). It is expected to correlate well with actual performance leading to the desired outcome because of its positive influence on the amount of effort and persistence that a person will apply to a given task [1]. Hence, students who report that they are confident about their ability to apply Web 2.0 technologies or higher order skills may be expected 
to perform well in future activities requiring the application of these skills.

Table1. Survey Items to assess student confidence with course tasks.

\begin{tabular}{|c|c|}
\hline Code & Question \\
\hline SE1 & $\begin{array}{l}\text { I am confident that, I can conduct access and } \\
\text { assess the quality of materials necessary to } \\
\text { conduct research on emerging technologies, } \\
\text { industries and companies }\end{array}$ \\
\hline SE2 & $\begin{array}{l}\text { I am confident that I can conduct a thorough } \\
\text { assessment of an emerging technology's } \\
\text { development and future prospects }\end{array}$ \\
\hline SE3 & $\begin{array}{l}\text { I am confident that I can conduct a thorough } \\
\text { analysis of the application of emerging } \\
\text { technologies in a specific business or non- } \\
\text { profit organization }\end{array}$ \\
\hline SE4 & $\begin{array}{l}\text { I am confident that I can work with a team to } \\
\text { analyze the feasibility of an emerging } \\
\text { technology application. }\end{array}$ \\
\hline SE5 & $\begin{array}{l}\text { I am confident that I can work with a team to } \\
\text { assess the costs and benefits of deploying or } \\
\text { commercializing an emerging technology } \\
\text { application }\end{array}$ \\
\hline SE6 & $\begin{array}{l}\text { I am confident that I can quickly learn and } \\
\text { integrate blogs into my daily activities - in } \\
\text { and out of school }\end{array}$ \\
\hline SE7 & $\begin{array}{l}\text { I am confident that I can quickly learn and } \\
\text { integrate blogs to coordinate meetings and } \\
\text { activities with my teammates. }\end{array}$ \\
\hline SE8 & $\begin{array}{l}\text { I am confident that I can work with a team to } \\
\text { develop a strategy for deploying blogs in a } \\
\text { business setting. }\end{array}$ \\
\hline SE9 & $\begin{array}{l}\text { I am confident that I can quickly learn and } \\
\text { integrate Web } 2.0 \text { tools into my daily } \\
\text { activities - in and out of school }\end{array}$ \\
\hline SE10 & $\begin{array}{l}\text { I am confident that I can quickly learn and } \\
\text { integrate Web } 2.0 \text { tools to coordinate } \\
\text { meetings and activities with my teammates }\end{array}$ \\
\hline SE11 & $\begin{array}{l}\text { I am confident that I can work with a team to } \\
\text { develop and present a Web } 2.0 \text { prototype and } \\
\text { business case in a professional manner and } \\
\text { deliver it on time }\end{array}$ \\
\hline SE12 & $\begin{array}{l}\text { I am confident that I can work with a team to } \\
\text { develop a strategy for deploying Web } 2.0 \mathrm{in} \\
\text { a business setting. }\end{array}$ \\
\hline SE13 & $\begin{array}{l}\text { I am confident that I can create and propose } \\
\text { innovations using Web } 2.0 \text { technologies for } \\
\text { a wide range of organizations. }\end{array}$ \\
\hline
\end{tabular}

Volume X, No. 1, 2009 surveys in the two sections of the capstone class. The thirteen items from this survey are listed in Table one. Students were asked to rate their confidence level on a ten-point Likert scale ranging from one (Not at all confident) to ten (Totally confident). Two categories of questions were included in the survey. The first category of items (SE1 to SE5) referred to behaviors that involve the application of higher order thinking skills. The second category of items (SE6 to SE13) referred to behaviors that involve the application of blogging and Web 2.0 technologies in general.

Seventeen students in Fall 2007 comprised the group exposed to public blogging while eighteen students in Spring 2008 were exposed to a private blogging site. In Fall 2007, blogger.com was used as the public blogging site. Students created their own accounts using a simple sign up process provided by the site. All of the students were impressed with the simplicity of setting up their blog pages. Students also created accounts in the socialbookmarking site del.icio.us to develop annotated bibliographies for their papers. In Spring 2008, a tikiwiki implementation on a hosted web site was used as the private blogging site. This private site was established in response to requests by the Fall 2007 students for a private space in which to improve their blog postings with the instructor's help. This private tikiwiki site did not provide social bookmarking capabilities so this second group of students only used blogs in their knowledge construction efforts. Figures 1 and 2 provide examples of students' public and private blogs. 
Sandeep's Blog

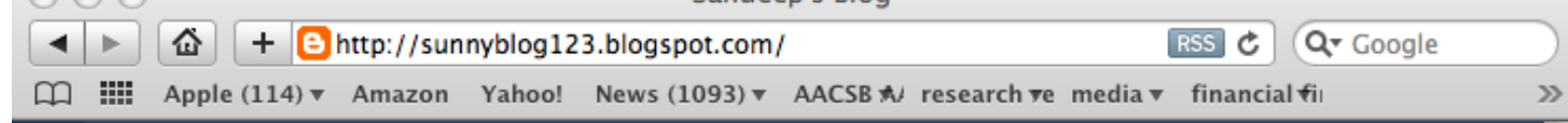

8. SEARCH BLOG a FLAG BLOG Next Blog* Create Blog I Sign In

\section{SANDEEP'S BLOG}

WEDNESDAY, DECEMBER 12, 2007

\section{Target IT - What I learned (Auto Industry Example)}

Web 2.0 was the focus of my work as I progressed through my Strategy in Information Systems course. My most valuable application of this technology was to the German luxury segment of the automotive industry in the U.S. (specifically focusing on three carmakers: Audi, BMW, and Mercedes-Benz), which was the subject of my final paper. A great example comes from automotive forums in which enthusiasts of particular car models can come together to share audio, video, and other information relating to their experiences with purchasing, driving, and maintaining those models. I was able to see how current industry players (Audi, Mercedes-Benz, and BMW) could capitalize on opportunities to better meet customers specific needs by analyzing requests or gripes posted by members on these enthusiast forums. Even more important is the fact that I was able to analyze how Web 2.0 technologies could modify the competitive factors in an industry. These factors are as follows: industry rivalry, threat of substitutes, power of buyers, power of suppliers, and barriers to entry. First, industry rivalry is greatly increased in the automotive industry when technologies such as forums are taken into account. This will happen because each auto maker can log-on to the opposing auto maker's forum and see what customer's needs have not been met and simply tailer initiatives to meet those needs. Second, the threat of substitutes decreases because auto makers can easily use forums to offer "group buy" discounts or special deals that lure potential customers away from substitute products. Third, the power of buyers increases substantially because consumers are able communicate their gripes or compliments about a certain
BLOG ARCHIVE

$\nabla 2007$ (6)

$\nabla$ December (1)

Target IT - What I learned (Auto Industry Example)...

- October (1)

- September (3)

August (1)

ABOUT ME

SANDEEP'S BLOG

VIEW MY COMPLETE PROFILE

Figure 1. Excerpt from a student's public blog 
HPDPtikiwiki : Credit Card Applications BI \& DP

4 命 + 鿒http://dprintcentral.com/tikiwiki/tiki-view_blog.php?blogld=47

RSS C. Google

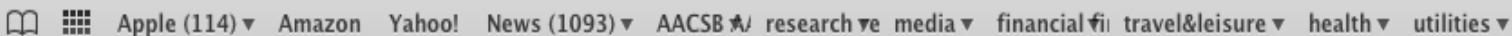
(34824 unread) AT\& ... Google Calendar International Associ.. HPDPwiki : Credit Ca.. HPDPtikiwiki : Credit.

\section{Welcome to HPDPtiklwiki}

\begin{tabular}{l}
\multicolumn{1}{c}{ Menu } \\
\hline Home \\
Users map \\
Image Galleries \\
Galleries \\
Rankings \\
Grile Galleries \\
List galleries \\
Home
\end{tabular}

可局 Powered

\section{Blog: Credit Card Applications BI \& DP}

Description: Digital printing is the future of commercial printing. Combine this with relevant Business Intelligence, and together it could become a very powerful marketing tool. Because digital printing has opened up the possibilities to a vast number of different substrates, companies are able to think outside the box of regular paper. They are to able to print on plastics, films, foils, textiles, and fabrics. With digital printing, the film or plate process is taken out of the equation, and printing is directly started right after the prepress stage. Traditional Printing: Pre-Press $\bullet$ Film/Plate $>$ Printing Digital Printing: PrePress Printing With digital printing, out put time is exceptionally faster and customization is extremely easier than in the past. I was recently tricked by a credit card company into actually giving them some of my time in reviewing one of their applications. I'm sure all of us has done this one time or another, fill out applications for free stuff. People offer you umbrellas, backpacks, mugs, and even subway sandwiches to fill out applications for credit cards. Once you fill one out, pretty soon you start getting tons and tons of junk mail saying that you are pre approve for this, and pre-qualify for that. I get tons of stuff like that and can pretty much spot them out without even opening them up. Those types of letters go right into the shredder. A few weeks back I was sorting through my mail and found a beautiful envelope with my name handwritten in calligraphy. I thought to myself , "WOW someone is getting married!". I carefully opened it and inside was a card wrapped around transparent paper, with the words "You're Invited!". Going one step further I found myself looking at a sample American Express Credit card with my name printed on it and an application to send in if I wanted to join. At this point I was like "what the heck!". I took a closer look at the envelope and upon examination my name was not handwritten, but expensively printed. Of course this very effecting marketing letter was digitally printed and customize to my name and address. As you can see, the combination of BI and DP will shape the way people are marketed to and how business will be able to reach out to the public. Bibliography Jordan, Cris. "Your essential guide to digital Drupa." Printing World. (April 16 2008): 23. Schwartz, Eugene G. "Effective Digital Print Strategies." Gene Therapy Vol. 3.11 12 Apr. 2008: 33-36.

Created by thevlegend on Wed 21 of May, 2008 [21:03]

Last modified Sun 25 of May, 2008 [21:23]

( 0 posts | 31 visits | Activity $=0.00$ )
Login

user:

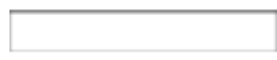

pass:

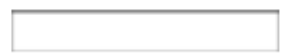

Page: $1 / 0$

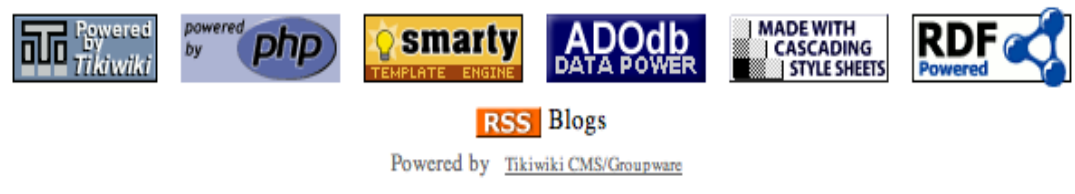

Figure 2. Excerpt from a student's private blog 
The course professor served as the system administrator for the tikiwiki site. Ease of sign up was comparable to that of blogger.com. Most of the complexity increase in this second implementation was on the administration side and experienced only by the professor teaching the course and administering the tikiwiki site. At the end of the Spring 2008 course, the professor gave the students the option of opting out of the posting of their blogs on the public web. None of the students requested an opt-out, hence the professor, as tikiwiki administrator, changed the access settings for the students' blogs for public web viewing.

\section{RESULTS}

Figure 3 compares scores for the two groups (private blog vs. private blog) in all of the items of the survey. Contrary to the study hypotheses, students in public blogs consistently reported greater confidence in both higher order thinking skills and the application of web 2.0 technologies.

Correlations among the survey items were high and positive, indicating that the items were redundant. Following the recommendations of Meyers et al. [11, page 376], we deleted redundant dependent variables and focused our analysis on two dependent variables that represented distinct skills: students' confidence that they can conduct a thorough assessment of an emerging technology's development and future prospects (item SE2), and students' confidence that they can quickly learn and integrate blogs into their daily activities - in and out of school (item SE6). Figure 4 compares the raw scores on these two items for the two groups in the study.

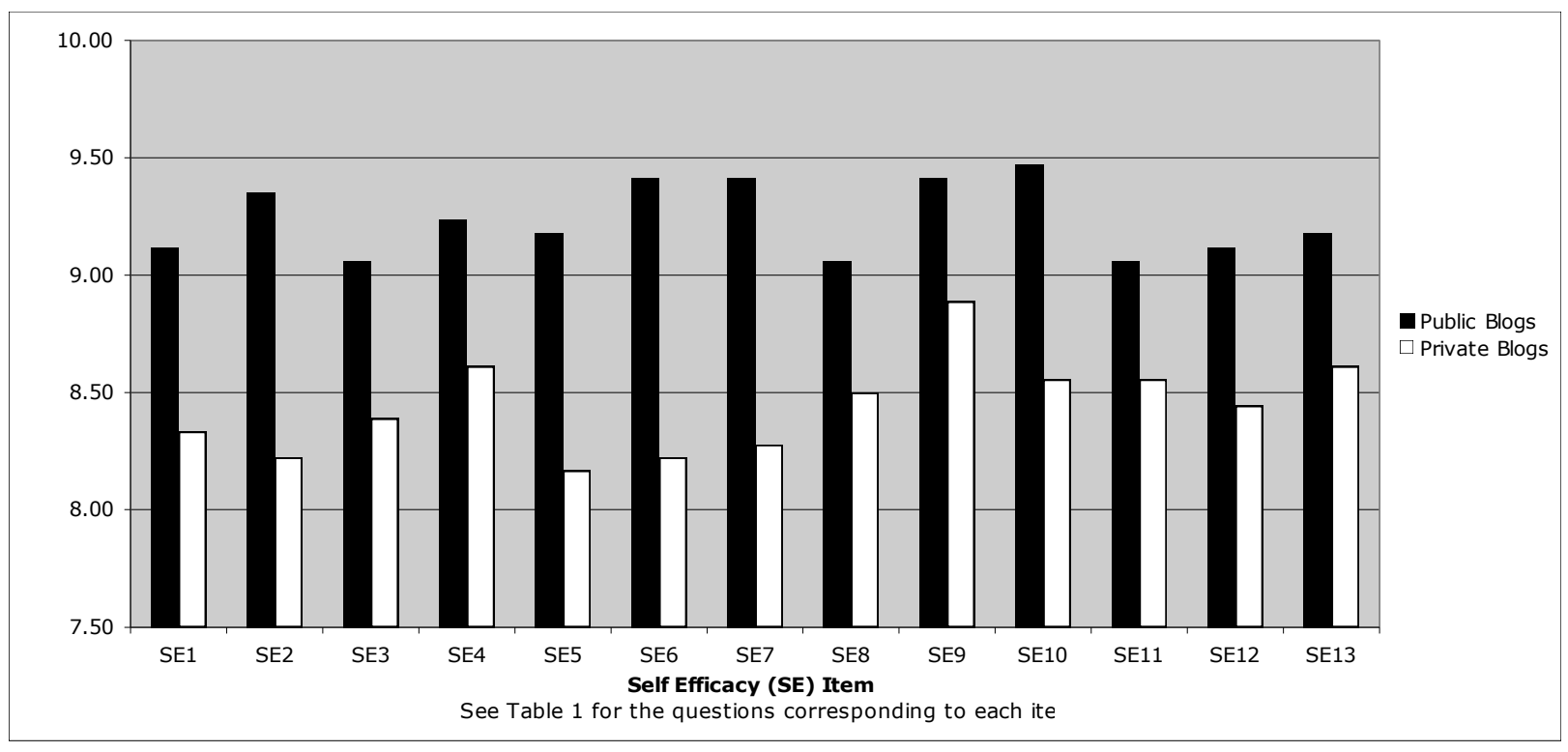

Figure 3. A Comparison of student ratings on all items in the Self Efficacy survey in relation to the blogging platform used in the course 


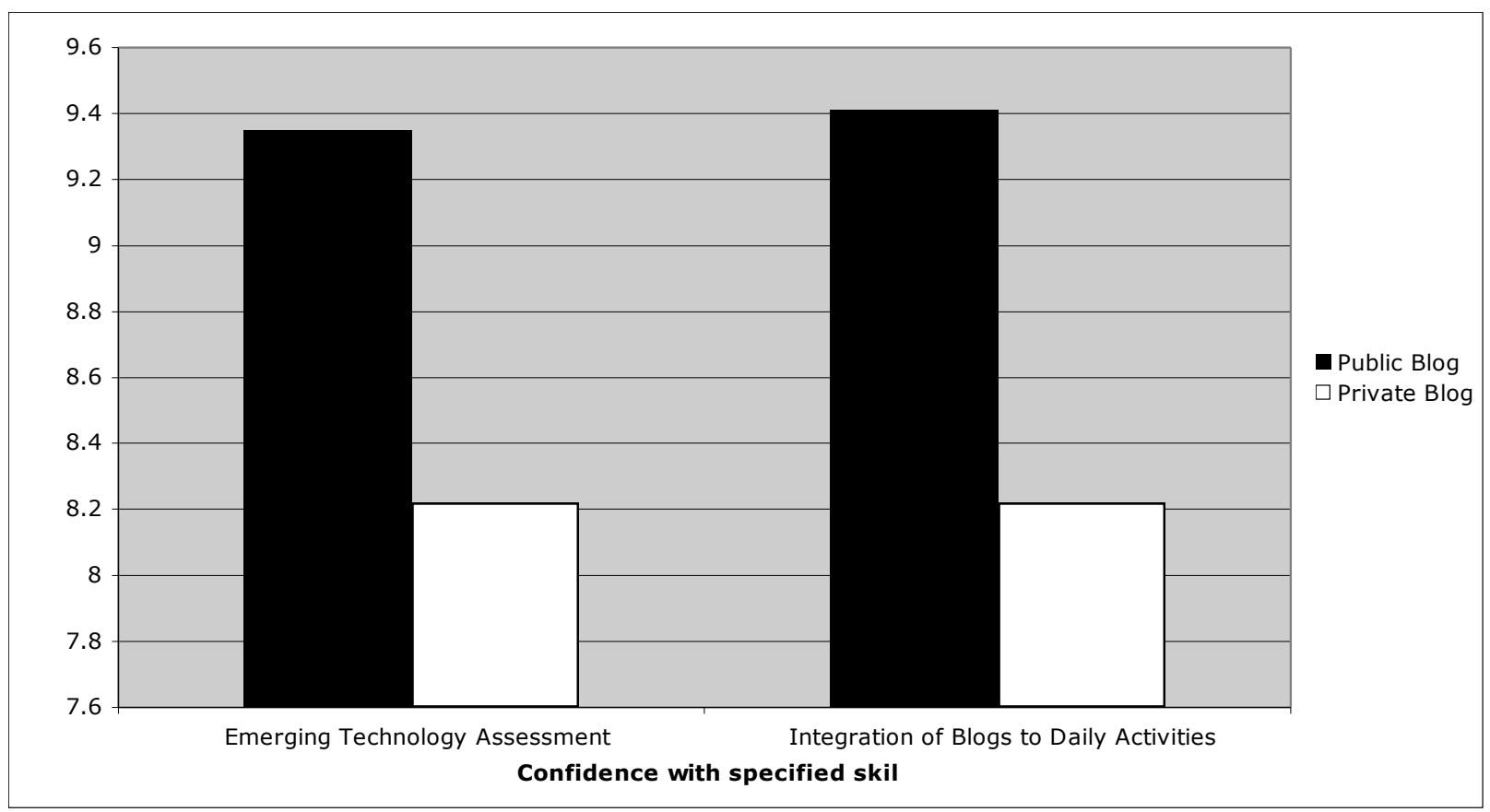

Figure 4. A comparison of student ratings of their confidence with course skills in relation to the blogging platform used in the course

A two-group between-subjects multivariate analysis of variance (MANOVA) was conducted on the two dependent variables: students' confidence with assessing the potential of an emerging technology; and students' confidence with the application of blogs to daily activities. The independent variable was blogging platform used (public or private). Using Wilk's criterion (see Table 2), the composite dependent variate was significantly affected by type of blogging platform (Wilk's lambda, $\mathrm{F}[2,32]=$ $4.263, \mathrm{p}<.024$, partial eta squared $=0.21$ ).

Univariate analyses of variance (ANOVAs) were conducted on each dependent measure separately to determine the locus of the statistically significant multivariate effect. Blogging platform was significantly associated with both confidence with applying emerging technology assessment $(F[1,33]=$ $6.472, \mathrm{p}<.02$, partial eta squared $=.164$ ) and confidence with applying emerging Web 2.0 technologies $(F[1,33]=7.392, p<.015$, partial eta squared $=.183$ ). Means and standard deviations of the two dependent variables for the two groups are presented in Table 3. Students in the public blog group reported more confidence with emerging technology assessment $(\mathrm{M}=9.35, \mathrm{SD}=0.862)$ than students in the private blog group $(\mathrm{M}=8.22, \mathrm{SD}=$ 1.629). Students in the public blog group reported more confidence with integrating blogs into their daily activities $(M=9.41, S D=0.939)$ than students in the private blog group $(\mathrm{M}=8.22, \mathrm{SD}=1.555)$.

Table 2. Multivariate and Univariate Analysis of Variance for Self Efficacy Measures

\begin{tabular}{|c|c|c|c|c|}
\hline & \multicolumn{2}{|c|}{$\begin{array}{c}\text { Multi- } \\
\text { variate }\end{array}$} & \multicolumn{2}{c|}{ Univariate } \\
\hline Source & df & $\mathbf{F}^{\mathbf{a}}$ & $\begin{array}{c}\text { Emerging } \\
\text { Technology } \\
\text { Assessment }^{\mathbf{b}}\end{array}$ & $\begin{array}{c}\text { Integrating } \\
\text { Blogs to } \\
\text { Activities }^{\mathbf{b}}\end{array}$ \\
\hline $\begin{array}{c}\text { F ratios } \\
\text { for blog } \\
\text { platform }\end{array}$ & 2 & $4.263^{*}$ & $6.472^{*}$ & $7.392^{*}$ \\
\hline MSE & & & 1.727 & 1.674 \\
\hline
\end{tabular}

Note: Multivariate F ratios were generated from Wilk's criterion.

a. Multivariate $\mathrm{df}=2.32$.

b. Univariate $\mathrm{df}=1,33$.

$* \mathrm{p}<.05$ 
Table 3. Mean Scores and Standard Deviations for Measures of Students' confidence with emerging technology assessment and Application of blogs to daily activities

\begin{tabular}{|c|c|c|c|c|}
\hline & \multicolumn{2}{|c|}{$\begin{array}{c}\text { Emerging } \\
\text { Technology } \\
\text { Assessment }\end{array}$} & \multicolumn{2}{c|}{$\begin{array}{c}\text { Integrating Blogs } \\
\text { to Daily Activities }\end{array}$} \\
\hline Group & $\mathbf{M}$ & SD & M & SD \\
\hline $\begin{array}{c}\text { Public } \\
\text { Blogs }\end{array}$ & 9.35 & 0.862 & 9.41 & 0.939 \\
\hline $\begin{array}{c}\text { Private } \\
\text { Blogs }\end{array}$ & 8.22 & 1.629 & 8.22 & 1.555 \\
\hline
\end{tabular}

The analysis shows that the differences depicted in Figure 4 are statistically significant. The findings show an opposite effect from that predicted in hypotheses one and two. Contrary to the hypotheses, students in the public blogging condition reported more confidence in both higher order thinking skills and integration of Web 2.0 technologies into their daily activities than students in the private blogging condition. Based on eta squared, blogging platform is accounts for about $16 \%$ of the variability in student self-reported confidence with emerging technology assessment, and for about $18 \%$ of the variance in student self-reported confidence with integrating blogs into their daily activities.

As with every field experiment, these significant findings have to be tempered by the fact that it is impossible to fully control a field situation. Although one instructor taught both groups of students, the classes were conducted in different semesters with different groups of students. Much variation could stem from these as well as from differences in the topics students blogged about, and differences in the user experiences provided by the blogging platforms used. Most significantly, the private blogging platform did not include a social bookmarking capability. This capability may have played a role in enhancing the effectiveness of the public blogging platform. Future work in controlled settings will help strengthen and test the findings of the study reported here.

\section{CONCLUSIONS}

The results of this study suggest that the public vs. private dimension of blogs plays a significant part in the effectiveness of these technologies' application in classes involving millennials. Surprisingly, and in contrast to students' own preferences, public blogging was more effective than private blogging for building students' confidence with their higher order thinking skills and application of web 2.0 technologies. This suggests that the benefits of formative assessment may have been outweighed by the raised expectations and stress associated with a general public display of one's blog. This stress and higher expectation may have also encouraged the students to pay greater attention to the first versions of their blogs, particularly since they were primed by the instructor - using course materials such as HBSP's "We Googled You" [5] -- that anything published on a public blog becomes part of their permanent public records.

This study shows that blogs can be effective means of helping students learn higher-order thinking skills and build facility with integrating technologies into their daily activities. This suggests great potential for blogs and other Web 2.0 technologies for enhancing the learning of the millennials that we currently find in our classrooms. Furthermore, the finding that public blogs appear to be more effective than private blogs eases the integration of these technologies into the classroom. Professors will be able to set up these services with little knowledge of system administration or even much assistance from computing services staff. Most Web 2.0 technologies are available via free or low-cost web services accessible via a web browser. These services offer easy sign-up procedures, friendly user interfaces, and a wide variety of pre-formatted templates. The high degree of creativity in the Web 2.0 community often means that innovative applications - e.g. microblogging, social bookmarking -- appear on the public platform before being integrated into private platforms like learning management systems (e.g. Blackboard). All these amount to a relatively easy integration of the most innovative technologies into classroom activities. The findings of this paper show that this low overhead implementation is effective for enhancing student confidence with the application of Web 2.0 technologies and higher order thinking skills.

\section{REFERENCES}

1. Bandura, A. (1977). Self-efficacy: toward a unifying theory of behavioral change. Psychological Review. 84(2), 191-215.

2. Bloom, B. S. (1956) Taxonomy of educational objectives, handbook 1: cognitive domain. New York, NY: David McKay Company, Inc.

3. Compeau, D., \& Higgins, C. (1995). Computer self-efficacy: development of a measure and an initial test. MIS Quarterly, 19(2), 189-211.

4. Computing \& The Internet National Study (2009). Student Monitor. Available: www.studentmonitor.com/computing.php 
5. Coutu, D.L. (2007, June 1). We googled you (HBR case study). Harvard Business Review.

6. Coutu, D.L., Palfrey, J.G., boyd, d.m., Joerres, J.A., \& Fertik, M. (2007, June 1). We Googled You (HBR Case Commentary). Harvard Business Review.

7. Howe, N. \& Strauss, W. (2000). Millennials rising: the next great generation. New York, NY: Vintage Books.

8. Jones, S. \& Fox, S. (2009, January 28). Generations online in 2009. Pew Internet Project Data Memo. Available: www.pewinternet.org/pdfs/PIP_Generations_200 9.pdf

9. Jones, S. (2002, September) The internet goes to college: how students are living in the future with today's technology. Pew Internet \& American Life Project. Available: pewinternet.org/pdfs/PIP_College_Report.pdf

10. Kuhlthau, C. C. (2003). Seeking meaning: a process approach to library and information services. Santa Barbara, CA: Libraries Unlimited.

11. Meyers, L.S., Gamst, G., \& Guarino, A.J. (2006). Applied multivariate research: design and interpretation. Thousand Oaks, CA: Sage Publications.

12. More than half of myspace visitors are now age 35 or older, as the site's demographic composition continues to shift (2006, October 5). Available:

/www.comscore.com/press/release.asp?press $=10$ 19

13. Oblinger, D. (2003, July/August). Boomers, genxers, millennials, understanding the new students. EDUCAUSE Review.

14. O'Reilly, T.O. (2006, February 10). Web 2.0 compact definition: trying again. Available: radar.oreilly.com/archives/2006/12/web-20compact.html

15. Prensky, M. (2001) Digital natives, digital immigrants. On the Horizon, 9(5). 